\title{
Three Contributions to Experimental Economics
}

\author{
Dissertation \\ zur Erlangung des wirtschaftswissenschaftlichen Doktorgrades der \\ Wirtschaftswissenschaftlichen Fakultät der Georg-August-Universität Göttingen
}

vorgelegt von

Cornelius Albrecht Schnitzler aus Friedrichshafen

Göttingen, 2013 
Erstgutachterin:

Zweitgutachter:

Drittprüfer:

Tag der mündlichen Prüfung:
Prof. Dr. C. Keser

Prof. Dr. S. Dierkes

Prof. Dr. G. Rübel

9. September 2013 


\title{
Essay I
}

\section{Rich man and Lazarus - Asymmetric endowments in public- goods experiments}

Joint work with Claudia Kesera, Andreas Markstädtera and Martin Schmidta

\begin{abstract}
In a series of experiments, we compare voluntary contributions to a public good in a symmetric setting to those in two asymmetric settings, where the players have different, randomly allocated endowments. We distinguish between a weakly and a strongly asymmetric situation. We observe that the group contribution levels are not significantly different between the symmetric and the weakly asymmetric situation. In both situations, participants tend to contribute the same percentage of their respective endowment. In the strongly asymmetric situation, where one of the players has a higher endowment than the three other players together, we observe a significantly lower group contribution level than in the other situations. The "rich" player in this situation does not contribute significantly more than the average contribution of the "poor" players and thus contributes a significantly lower percentage of his endowment. He is not as greedy as the rich man in the parable but leaves not more than "breadcrumbs" to the poor players.
\end{abstract}

Keywords: Experimental economics; public goods; asymmetric endowments.

The official version of the paper has been published as a discussion paper in the CIRANO Scientific Series and is available at http://www.cirano.qc.ca/pdf/publication/2013s-32.pdf

aGeorg-August-Universität Göttingen, Department of Economics, Platz der Göttinger Sieben 3, 37073 Göttingen, Germany. 


\title{
Essay II
}

\section{Custom-made healthcare - An experimental investigation}

Joint work with Claudia Kesera, Claude Montmarquetteb and Martin Schmidta

\begin{abstract}
In this paper, we investigate in a controlled laboratory experiment physician behavior in the case of payment heterogeneity. In the experiment, each physician provides medical care to patients whose treatments are paid for either under fee-for-service (FFS) or capitation (CAP). We observe that physicians customize care in response to the payment system. A FFS patient receives considerably more medical care than the corresponding CAP patient with the same illness and treatment preference. Physicians over-serve FFS patients and under-serve CAP patients. After a CAP payment reduction in the experiment we observe neither a quantity reduction under CAP nor a spillover into the treatment of FFS patients.
\end{abstract}

Keywords: Experimental economics; physician reimbursement; capitation; FFS; customization; fee regulation.

Acknowledgements: We thank Nathalie Viennot and Julie Heroux for their excellent technical assistance and administrative support.

The official version of the paper has been published as a discussion paper in the CIRANO Scientific Series and is available at http://www.cirano.qc.ca/pdf/publication/2013s-15.pdf

aGeorg-August-Universität Göttingen, Department of Economics, Platz der Göttinger Sieben 3, 37073 Göttingen, Germany.

bCenter for Interuniversity Research and Analysis on Organizations, 2020, University St., 25th Floor, Montreal, Quebec, H3A 2A5, Canada. 


\title{
Essay III
}

\section{Money talks - Paying physicians for performance}

Joint work with Claudia Kesera

\begin{abstract}
Pay-for-performance has been enjoying a growing popularity among healthcare policy makers. It attempts to tie physician payment to quality of care. In a controlled laboratory experiment, we investigate the effect of pay-for-performance on physician provision behavior and patient benefit. For that purpose, we compare two payment systems, a traditional fee-for-service payment system and a hybrid payment system that blends fee-for-service and pay-for-performance incentives. Physicians are found to respond to pay-for-performance incentives. Approximately 89 percent of the participants qualify for a pay-for-performance bonus payment in the experiment. The physicians' relative share of optimal treatment decisions is significantly larger under the hybrid payment system than under fee-for-service. A patient treated under the hybrid payment system is significantly more likely to receive optimal treatment than a fee-for-service patient of matching type and illness. Pay-for-performance in many cases alleviates over- and under-provision behavior relative to fee-for-service. We observe unethical treatment behavior (i.e., the provision of medical services with no benefit to the patient), irrespective of the payment system.
\end{abstract}

Keywords: Experimental economics; physician remuneration; pay-for-performance (P4P).

Acknowledgements: We thank Martin Schmidt for his excellent programming assistance.

The official version of the paper has been published as a discussion paper in the CEGE series and is available at wwwuser.gwdg.de/ cege/Diskussionspapiere/DP173

aGeorg-August-Universität Göttingen, Department of Economics, Platz der Göttinger Sieben 3, 37073 Göttingen, Germany. 